\title{
Os desafios e a afirmação de uma revista científica
}

\author{
The challenges and consolidation of a scientific journal
}

\author{
Jefferson Pedro Piva ${ }^{1}$, Pedro Celiny Garcia ${ }^{2}$, Danilo Blank ${ }^{2}$, Sérgio Amantéa ${ }^{3}$
}

$\mathbf{E}_{x}$ cas no mundo e, mesmo assim, este é um mercado ainda em expansão. Trata-se de um mercado exigente, competitivo e pouco tolerante ou complacente com equívocos. Isto explica o surgimento e também a saída de circulação de revistas médicas a cada mês. Mas que mercado é este? Quais são as regras que o regulamentam? Quais são seus componentes?

Os clientes de uma revista médica estão distribuídos em pelo menos três grupos: os leitores, os colaboradores e os patrocinadores. Conquistar e harmonizar os interesses destes grupos permite que uma revista científica torne-se respeitada, lida e auto-sustentável. $\mathrm{O}$ desequilíbrio conseqüente ao predomínio dos interesses de um destes grupos sobre os demais poderá acarretar problemas tais como: elitização, perda de credibilidade, dúvidas quanto à isenção e falta de impacto.

Atingir tal equilíbrio é o grande desafio para a estabilidade e o crescimento de uma revista científica. Inicialmente, o corpo editorial precisa descobrir e atrair seus clientes. No caso do Jornal de Pediatria, devemos intuir (antever, imaginar) os interesses dos quase 15.000 assinantes, para que se tornem realmente leitores. Ao mesmo tempo, obter o reconhecimento e nos tornarmos atraentes para que os pesquisadores dos mais diversos centros de pesquisa do país veiculem preferentemente seus trabalhos em nossa revista. Por outro lado, precisamos viabilizar o custo de produção e distribuição, que se tem mantido constante nos últimos anos: ao redor de quarenta mil dólares americanos por tiragem; o que significa mais de trezentos mil dólares anuais (seis números regulares e dois suplementos). Para que tenhamos uma qualidade editorial mantida, este aporte financeiro é vital.

Identificados os componentes (clientes), como avaliar sua satisfação? Quais os marcadores para verificar seu interesse e a qualidade do produto oferecido?

1. Editor do Jornal de Pediatria.

2. Editores associados do Jornal de Pediatria.

3. Membro do Conselho Editorial do Jornal de Pediatria.
O fato de distribuir o Jornal de Pediatria a mais de 15.000 assinantes significa que todos estes estejam interessados ou realmente lêem os artigos ali veiculados? Como saber se a temática e os rumos escolhidos são os mais adequados às expectativas dos leitores? Esta é uma resposta realmente difícil de se obter por meio da revista impressa. Entretanto, quando observamos os acessos ao JPED, a versão eletrônica do Jornal de Pediatria (www.jped.com.br), estas dúvidas são facilmente dirimidas. No mês de outubro passado, apenas sete meses depois do lançamento de nosso site, ocorreram cerca de quinze mil acessos. Isto corresponde a 500 acessos diários ao JPED, com uma média de onze minutos e meio, tendo sido solicitados mais de 4.000 downloads nesse mês. O progressivo aumento no número de acessos e a consistência desta progressão nos fazem crer que, de alguma forma, estamos atendendo aos interesses dos leitores do Jornal de Pediatria.

A análise dos acessos ao JPED nos sinaliza também que a internacionalização de nossa revista é um fato, pois registramos um progressivo aumento no número de visitantes de países como Uruguai, México, Portugal, Argentina, Arábia Saudita, Nova Zelândia, Reino Unido, Alemanha e Estados Unidos. Deve-se destacar que ainda não colocamos totalmente em prática o plano de divulgação internacional, que está planejado para 2002, com o qual se espera que o número de acessos internacionais aumente mais ainda.

O número de leitores e a ampla distribuição de nossa revista representam um grande atrativo aos pesquisadores para veicular suas pesquisas. Entretanto, além de leitores, os periódicos científicos devem oferecer credibilidade e respeitabilidade. Para nossa satisfação, o Jornal de Pediatria vem conquistando progressivamente vários marcadores de qualidade. Temos sido reiteradamente indicados pelos centros de pesquisas, dentro das câmaras técnicas da CAPES (Coordenadoria de Aperfeiçoamento de Pessoal de Nível Superior), como sendo a revista pediátrica nacional de eleição para a veiculação de suas pesquisas. Baseados em avaliação minuciosa realizada pelo CNPq (Conselho Nacional de Pesquisa), fomos agraciados com uma verba 
suplementar como forma de incentivo e reconhecimento da importância de nossa revista para a pesquisa brasileira. Em recente reunião, com a participação de membros da CAPES, de diversos cursos de pós-graduação e editores de revistas médicas, o Jornal de Pediatria foi indicado para compor uma comissão, com representantes destas três instâncias e coordenadas pela BIREME, com o objetivo de organizar um sistema de avaliação e graduação das diversas revistas médicas nacionais. Esta proposiçãoé extremamente pertinente e necessária, pois, a exemplo do que existe internacionalmente, poderemos quantificar o impacto de cada uma das revistas nacionais. Este ranking certamente servirá como estímulo para uma saudável competição pelo prestígio cada vez maior junto aos centros de pesquisas e seus pesquisadores.

Concomitante ao reconhecimento e incentivo do CNPq, da CAPES e de suas câmaras técnicas, tivemos a confirmação da inclusão do Jornal de Pediatria na Biblioteca Científica Eletrônica On-line, SciELO (www.scielo.org), gerenciada em parceria pela Fundação de Amparo à Pesquisa do Estado de São Paulo (FAPESP) e pelo Centro LatinoAmericano e do Caribe de Informação em Ciências da Saúde (BIREME), que organiza bases de dados bibliográficos e de edições completas de periódicos científicos. O Jornal de Pediatria foi um dos onze periódicos da área da saúde, que estão ainda fora do Index Medicus, selecionados para inclusão no SciELO.

O Jornal de Pediatria está indexado nas bases de dados EMBASE, LILACS e agora no SciELO. Nosso grande desafio é retomar a indexação no Index Medicus, perdida nos anos 70. Diferentemente do que muitos imaginam, a inclusão no Index Medicus não depende somente da qualidade dos artigos publicados no periódico pretendente. Por ser uma base de dados de periódicos voltada ao interesse do mercado norte-americano e, secundariamente, ao mercado europeu, a inclusão de novos títulos depende também de fatores como: possível interesse dos leitores (prioritariamente norte-americanos), número de periódicos com o mesmo tema central já aceitos nesta base de periódicos, assuntos veiculados e publicados no periódico pretendente, etc. Temos convicção de que nossa inclusão na base de dados SciELO, associado aos marcadores de nossa página na Internet, promoverão uma ampliação de nossa divulgação nacional e internacional, o que, em um futuro não muito distante, possibilitará também nosso retorno ao Index Medicus.

Por outro lado, o progressivo reconhecimento da qualificação do Jornal de Pediatria tem sido acompanhado pelo crescimento sólido e persistente do volume de artigos submetidos. Tomando por base apenas os artigos originais submetidos nos anos 1999, 2000 e 2001, observa-se um total anual de 174,180 e 210 , respectivamente; sendo $65 \%$ destes artigos originais oriundos de São Paulo, Rio Grande do Sul e Rio de Janeiro. A taxa de recusa tem ficado em torno de $35 \%$, não se observando qualquer influência dos estados de origem dos artigos.
Dentro do equilíbrio proposto, devemos ter um especial cuidado com a viabilidade financeira. Neste aspecto, independentemente das crises econômicas enfrentadas, $\mathrm{o}$ interesse da indústria tem-se mantido constante. $\mathrm{O}$ resultado final, nos últimos quatro anos, tem sido um desembolso de menos de três dólares americanos por sócio da SBP para receber os oito números de nossa revista.

Não raras vezes fomos questionados sobre a validade de manter uma dependência ou um vínculo tão forte com a indústria farmacêutica. O Estado de São Paulo publicou, em 15 de outubro de 2001, a matéria "Anúncios de remédios escondem riscos", que nos questionava quanto "à alta dependência da revista com relação aos laboratórios", afirmando ainda que "não menos preocupante, foi o achado que em apenas $20 \%$ dessas propagandas havia informações sobre aqueles fatores que trazem riscos para o paciente, como as reações adversas, as contra-indicações e as interações com outros medicamentos".

Primeiramente, deve ser dito que esta relação (anúncios em revistas médicas) está normatizada tanto pela Organização Mundial de Saúde (OMS), como pela Agência Nacional de Vigilância Sanitária (Anvisa), que estabelecem e vigiam as informações apresentadas neste tipo de publicidade especializada.

Um outro ponto que parece contraditório: é de se imaginar que qualquer leitor do Jornal de Pediatria médico ou profissional da área técnica especializada - que tenha discernimento para avaliar e julgar pesquisas na área médica, não vá buscar sua atualização ou informação nos espaços destinados a propagandas. Pelo menos dentro de periódicos especializados, isto é inconcebível.

Da referida reportagem, apesar de não dispormos de todos os dados coletados, mas apenas das conclusões do repórter e do pesquisador, depreendemos que: (a) o uso de recursos privados em apoio à pesquisa em nosso país é considerado, a priori e em alguns segmentos, uma associação suspeita e possivelmente maléfica (entretanto, este pressuposto se opõe a tudo o que se verifica em termos de ciência em todo o mundo); (b) uma parcela considerável de anunciantes tem o "mau hábito" de reincidir no desrespeito à legislação vigente. De qualquer modo, tivemos a oportunidade de repetir o levantamento publicado no referido periódico e, mesmo obtendo resultados muito inferiores ao que foram divulgados, concluímos pela necessidade de um policiamento mais criterioso na observância das normas por parte dos anunciantes.

Pelo acima exposto, parece claro que os rumos adotados pelo Conselho Editorial do Jornal de Pediatria têm encontrado respaldo e um perfeito equilíbrio nos interesses de nossos leitores, dos pesquisadores e, também, por parte da indústria e dos órgãos patrocinadores. A manutenção deste equilíbrio é um dos fatores que nos permite vislumbrar um horizonte promissor e uma afirmação cada vez maior neste competitivo e exigente mercado das publicações médicas. 